heterozygous for familial hypercholesterolemia. Amer. J. Dis. Child. 1.31: 162 (1977)

12. Lipid Research Clinics Program: Manual of Laboratory Operations. Vol. 1 (United States Government Printing Office, Washington, D.( .. 1974).

1.3. Snedecor, (;. W., and Cochran, W. G.: Statistical Methods, Fd. 6, p. 128 (Iowa State University Press. Ames, Iowa, 1967)

14. Snedecor. (;. W.. and Cochran. W. (;.: Statistical Methods. Fd. 6. p. 172 (Iowa State University Press. Ames, Jowa, 1967)

15. Snedecor. (3. W.. and Cochran. W. G.: Statistical Methods, Fd. 6, p. 194 (lowat State University Press. Ames, lowa. 1967).

16. The steps described in this manuscript were done with the formal approval of the University of Cincinnati Faculty Committec on Human Research and the General Clinical Research Center Advisory (inmmittec, and with signed informed consent.

17. A portion of this work was supported by the General Clinical Reseateh Center cirant RR (00068-14, and a portion of this work was done during Dr. Glueck's tenure as an Estahlished Investigator of the American Heart Association, 1971-1976.

18. Requests for reprints should he addressed to: ( J. J. (ilueck. M.D., University of Cincinnati, General Clinical Reseatreh (enter. ('incinnati General Hospital. 2.34 (joodman St., (incinnati, Ohio 45267 (USA)

19. Received for publication December 17, 1976 .

20. Accepted for publication February 15, 1977.

\title{
Low and High Density Lipoprotein Cholesterol Interrelationships in Neonates with Low Density Lipoprotein Cholesterol $\leq$ the 10th Percentile and in Neonates with High Density Lipoprotein Cholesterol $\geq$ the 90th Percentile
}

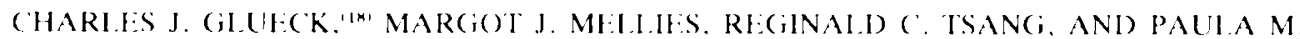 \\ SIIINI:R
}

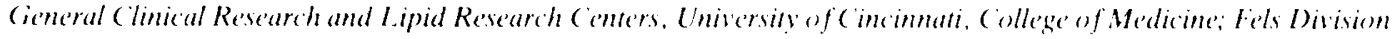
of Pe'diatric Research. ('hildre'n's Hospital Rescardh Foundation, (incinnati. ()hic), USA

\section{Summary}

Since the inverse relationship between high density lipopro. tein cholesterol (C-HDI.) and low density lipoprotein cholesterol (C-L.DI) is generally recognized in school children and in adults, but not at birth, the current study was focused on neonates having $C$-HDL $:$ the 90 th percentile and neonates with $C$. LDL $\leq$ the 10 th percentile to determine whether any distinctive relationships existed at the extreme limits of the frequency distribution among C-HDL, C-L.DL, and total plasma cholesterol. Sixty-three neonates with $C$-LDL $\subseteq$ the 10 th percentile $(20 \mathrm{mg} / \mathrm{dl}$ ), and 58 with $\mathrm{C}$-HDI. the 90 th percentile $(50 \mathrm{mg} /$ dl) were selected in the consecutive order of their birth as part of an ongoing cord blood lipid and lipoprotein survey. Comparisons of the hypobeta- and hyperalphalipoproteinemic neonates with 117 previously described unselected neonates were made. In the 117 unselected neonate controls, both $\mathrm{C}$-HDI. and CLDL levels were closely correlated with total cord blood cholesterol $(r=0.63,0.76, P<0.01)$, whereas $C$-HDL was not significantly related to $C$-LDL $(r=0.002)$. In the 63 hypobetalipoproteinemic neonates, C-HDL correlated closely with total plasma cholesterol concentrations $(r=0.98, P=0.01)$. C.I.DI. failed to correlate with total plasma cholesterol $(r=0.07)$. In the face of low cord blood C.I.DL, nearly all of the total plasma cholesterol variation was accounted for by C-HDL. C-HDL was not significantly related to C-L.DI. $(r=-0.15)$. In 58 hyperalphalipoproteinemic neonates, C.HDL did not significantly correlate with total cholesterol concentrations $(r=\mathbf{0 . 2 2})$, whereas C-LDI, was closely related $(r=0.88, P-0.01)$, with nearly all of the total plasma cholesterol variation accounted for by $C$. I.DL. The inverse C-HDL, to C-I.DI, relationship was not significant $(r=-0.18)$

\section{Speculation}

Whatever factors contribute to both the overall and to the extremes of the C-HDL and C-L.DL frequency distributions at birth, C-HDL and C-LDL in neonates appear to be under independent metabolic control.

Plasmat high density lipeprotein cholesterol levels in adults are often inversely correlated with low density lipoprotein cholesterol levels $(1,3,7,8)$. In the Bogalusa lipoprotein study in white and black school children, total plasma cholesterol and ( 1.DI. levels were closely correlated $(r=0.745 .0 .727)(12)$. Total plasma cholesterol also correlated with (-HDL concentrations in whites and blacks $(r=0.4+1, r=0.595)(12)$. The Bogalusa study (12) revealed significant inverse relationships between (-HDI and (-1.DI. levels in $117+$ black children $(r=$ $-0.09)$. and in 2009 white children $(r=-0.231)$. The correlattion in black children $(r=-0.09)$ between $(-H D)$ and ( - L.DI. although statistically significant, is low, and perhaps of douhtful biologic import. Rhoads et al. (9) found no significant correlation between $(-1$ ID)I and $(-1 . D) .(r-0.01)$ and concluded that "the inverse relation of alpha cholesterol to prevalence of coronary heart discase was independent of heta cholesterol . . . " (9). 
In cord blood. C-HDL accounts for about one-half of total plasma cholesterol (13), in contrast to older children (12) and adults $(1,2,7,8)$ where $C$-HDL makes up less than one-third of total plasma cholesterol levels. In our recent study of 117 unselected neonates. cord blood C-HDL levels did not correlate with C-LDI $(r=-0.002)$, whereas C-HDL and C-L.DI. concentrations correlated closely with total plasma cholesterol $(r=0.63, r$ $=0.76, P<0.001)(5)$. Since the inverse relationship between C-HDL and C-LDL is generally recognized in school children (12) and in adults $(1,3,7,8)$, but not at birth (5), the current study was focused on neonates having (-HDL the 90th percentile and neonates with C-L.DL $\leq$ the 10 th percentile to determine whether distinctive inverse relationships between $\mathrm{C}$ HDI. and (-I.DI. existed at the extreme limits of the frequency distribution.

\section{MATERIAIS AND METHODS}

PATILNTS

Sixty-three neonates with (-L.DL $\leq$ the 10 th percentile (20) $\mathrm{mg} / \mathrm{dl})(1.3)$, and 48 with $(-\mathrm{HDL} \geq$ the 90 th percentile $(50 \mathrm{mg} /$ d1) (6) were selected in the consecutive order of their birth as part of an ongoing cord blood lipid and lipoprotein survey. Use of the 10th percentile (C-L.DI.) and the 90th percentile (CHDL) for the identification of neonatal hypobeta- and hyperalphalipoproteinemia, although based on neonatal population data (6). was arbitrary, and might not be customarily synonymous with other definitions of the disorders. Cord blood cholesterol. (-HDL. and (-LDL. were quantitated as previously described (16). There was no known bias in selection of the neonates who were entered into the study consecutively in order of their live birth. with informed parental consent. There was no selection on the hasis of maturity, birth weight. or perinatal stress factors (15).

\section{STATISTICAL. ANALYSES}

Comparisons of the hypobeta- and hyperalphalipoproteinemic neonates with 117 previously described unselected neonates (5) were made using the $t$-test (10). Relationships between lipid and lipoprotein classes were assessed by regression analysis (11).

\section{RFSULTS}

C-HDL. (-LDL. AND TOTAL PI.ASMA CHOI.FSTEROL. IN HYPOBETA-. HYPERAI.PHAI.IPOPROTEINEMIC NEONAIES, AND CONTROI.

$$
\text { SUBJECTS }
$$

As summarized in Table 1 , children selected by C-LDL $s$ 10th pereentile had lower plasma total cholesterol levels. and similar plasma (-HDL levels when compared to the 117 unselected neonatal controls.

Children selected hy $C-H D L \geq$ the 90 th pereentile had plasma total cholesterol levels which were higher, and plasma (-L.DL levels which were lower than those in the 117 neonatal control subjects, $P<0.01$.

(-HDL AND (-LDL RELATIONSHIPS: HYPOBLTA-AND HYPERALPHALIPOPROTEINFMIC NFONATFS AND CONTROI. SUBJECTS

As summarized in Table 2, relationships between C-HDL and total cholesterol. (-I.DI, and total cholesterol, and (-HDI and C-LDL were different for control, hypobeta-, and hyperalphalipoproteinemic neonates. In the 117 unselected newborn control subjects, both C-HDL and C-LDL levels were closely correlated with total cord blood cholesterol $(r=0.63, r=0.76, P<0.01)$. whereas $\mathrm{C}$-HDL was not significantly related to $(-\mathrm{L}$.DL. $(r=$ $-0.0(0)$ ).

In the 6.3 hypobetalipoproteinemic neonates, C-HDL correlated closely with total plasma cholesterol concentrations $(r=$
Table 1. High density lipoprotein cholesterol (c-HDL), total plasma cholesterol, and low density lipoprotein cholesterol $1 C^{\circ}-$ L.DI.) in 117 unselected control neonate's, 6.3 neonate's with ('$L . D L \leq 20 \mathrm{mg} / \mathrm{dl}$, and 58 neonates with $(-H D L . \geq 50 \mathrm{mg} / \mathrm{dl}$

$$
(\bar{X} \pm \mathrm{SE})
$$

Total plasma

Subjects (-HDL. mg/dl choclsterol. $\mathrm{mg} /$ dl C-LDL. mg/dl

$$
\begin{aligned}
& 117 \quad \text { Unselected } \\
& \text { controls } \\
& \text { (5.5 }
\end{aligned}
$$

$1 P<0.01$, as compared to 117 unselected control subjects.

Table 2. Interrelationships betwe'en high density ( $(-H D)$. $)$ and low density (C-L.DL) lipoprotein cholesterol, and total plasma cholesterol levels: 117 unslected neonatal control subject, 6.3 neonates with $(-I . D L . \leq 20 \mathrm{mg} / \mathrm{dl} ; 58$ neonate's with $(-H D) L$ $50 \mathrm{mg} / \mathrm{dl}$

\begin{tabular}{lccc} 
& \multicolumn{3}{c}{ Correlation coefficient $(r)$} \\
\cline { 2 - 4 } & $\begin{array}{c}\text { C-HDL: } \\
\text { total plasma } \\
\text { cholesterol. }\end{array}$ & $\begin{array}{c}\text { C-LDI: } \\
\text { total plasma }\end{array}$ & C-HDL: \\
Subjects & $0.63^{1}$ & $0.76^{1}$ & -0.002 \\
cted controls & $0.98^{1}$ & 0.07 & -0.15 \\
S.-LDI. $\leq 20$ & 0.22 & $0.88^{1}$ & -0.18
\end{tabular}

117 Unselected controls

58 Neonates, $(\cdot-H D L=50$

0.98

0.07

$-0.15$

$1 P<0.01$.

$0.98 . P<0.01)$. ( - LDL failed to correlate with total plasma cholesterol $(r=0.07)$. ('-HDL was not significantly related to C-I.DI. $(r=-0.15)$. Table 2 .

In 58 hyperalphalipoproteinemic neonates. (C-HD) did not significantly correlate with total cholesterol concentrations $(r=$ $0.22)$, while (-LDL was closely related $(r=0.88 . P<0.01)$. Table 2. The inverse (-HDL to (-L.DI. relationship was not significant $(r=-0.18)$. Table 2 .

\section{DISCUSSION}

Marked quantitative differences exist for C-HDI and C-I.DL in neonates compared with older children and adults $(2,4,5$. 12). Plasma C-HDI. levels in children and adults are increased only by about $40-50 \%$ from those at birth, whereas (-LDL. increases 4 -fold $(2,4,12-14)$. The ratio of C-HDL to (-I.DI. (about $1.2: 1$ at birth) (5) changes to $1: 2.4$ in adults (3.4). In children and adults, both (-L.DL and C-HDL correlate positively with total plasma cholesterol, whereas C-HDL usually, hut not invariably (9), correlates inversely with C-L.DI. (1.3.7. 8 . 12). This inverse correlation may be important since the $(-H D L$ is thought to be "antiatherogenic" whereas C-LDL is the predominant atherogenic lipoprotein (3-6,9).

In 117 unselected neonates the correlation coefficients for $(-$ HDI. to total cholesterol $(r=0.63)$, and (-LDL to total cholesterol $(r=0.76)$, were very similar to those reported for older children (12). The C-HDI, to (-LDL relationship was not significant in the 117 neonates $(r=-0.0(02)$. in contrast to the relationship in large groups of school children $(r=-0.231$ for 2009 whites, $r=-0.09$ for 1174 blacks (12).

In hypobetalipoproteinemic neonates, (-LDL failed to correlate with total plasma cholesterol. in contrast to unselected control neonates or older school children (12). However. (:HDL was closely related to total plasma cholesterol. resembling 
the relationship in control neonates or older children. In the face of low cord blood (-LDI, nearly all of the total plasma cholesterol variation was accounted for by (-HDI. The inverse (HIDI to (-I.DI correlation was not significant.

In hyperalphalipoproteinemic neonates. (-L.D) but not (HDL. correlated significantly with total plasma cholesterol. Nearly all of the total plasma cholesterol variation was accounted for by (-I.DI.. The inverse (-HD) to (-I.DI. relationship was not significant.

Whatever factors contribute to both the overall and to the extremes of the (-HDI and (-L.DI. frequency distributions at birth. (-HDI. and ('-I.DI. in neonates appear to be under independent metabolic control.

It might he interesting to follow into later infancy and childhood neonates at the extreme of the (-1.D)l. and (-11D)l distributions to determine whether or when. with the inevitable ascendence of (-L.DI. as the predominant cholesterol carrying lipoprotein (1-4), significant inverse (-HD) to (-I.DI. relationships will appear.

\section{(ONCLUSION}

In 117 unselected neonates the correlation coefficients for (HDI to total cholesterol $(r=0.6 .3)$, and (-I.DI to total cholesterol $(r=0.76)$ were very similar to those reported for older children. However, in contrast to school children, the ('-HDI. to C-I.DI, relationship in the unselected neonates was not signiticant $(r=-0.002)$. In 6.3 hypobetalipoproteinemic neonates. (1.DI failed to correlate with total plasma cholesterol levels $(r-$ $0.07)$, but (-HDL was closely related to total cholesterol $(r=$ 0.98). The inverse (-HDL to (-1.DI correlation was not significant. In 58 hyperalphalipoproteinemic neonates (-I.D) $(r=$ $0.88)$, but not $(-H D L,(r=0.22)$, correlated significantly with total plasma cholesterol. Nearly all of the total plasma cholesterol variation was accounted for by (-I.DI.. The inverse (HDL to (-L.DL relationship $(r=-0.18)$ was not significant. Whatever factors contribute to both the overall and to the extremes of the (-HDI. and C-L.DI. frequency distributions at birth, $(-H D L$ and (-LDL in neonates appear to be under independent metabolic control.
RIEFIRI:N(TS ANI) NOTIS

1. Carlson. I.. A.: L ipoprotein fractionation. J. Clin. Path. Suppl. 5. 20: 32 (197.3)

2. Fredrickson, D. S.. and I.evy. R. I.: Familial hyperlipoproteinemia In: J. 13. Stanhury, J. B. Wyngaarden, and D. S. Fredrickum: The Metaholic Basis of Inherited Diseane, Idd 3, pp. 545-614 (McCiraw-Hill Book ('o., New York. $1972)$.

3. Clueck. C. J . Alpha-lipoprotein cholesterol, beta-lipoprotein cholesterol. and Iongevity. Artery. 2(3): $196(1976)$

4. Glueck, ('. J.. Ciartside, P.. Fallat, R. W. Siclski, J., and Steiner. P. M. longevity sundromes: Familial hypobeta- and fitmilial heperalphatipopresteinemia J. Iah. ( lin. Med., 88: 941 (197h)

5. Cilueck. C. J.. (iartside, P. S.. Tiang. R. C.. Mellies, M. J.. and Steiner. P. M : Black-white similarities in cord bloced lipids and lipoproteins. Metatholism. 26: $347(1977)$

6. Gilueck, ( . J.. Tsang, R. C.. Mellies, M. J., and Steiner. P. M.: Neonatal familial hyperalphit-lipoproteinemiat. Metatolism, 26: 469 (1677)

7. Nichols. A. V.: Human serum lipoproteins and their relationships. Adsan. Biol. Med. Phys.. 11: 109 (1967).

8. Nikkilat, E.: Studies on lipid-protein relationships in mormal and pathological sera and effect of heparin on serum lipoproteins. Siand. J. (lin. 1.atb. Invent. Suppl. 5: $1(1053)$.

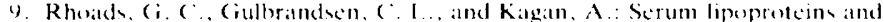
coronary heart disease in a population survey of Hawaii-Japanese men. New Fingl. J. Med.. 244: 293 (1976).

10. Snedecor. (i. W.. and cochran. if. (i.: Stattstical Methods, Idd. h. p. se (Iowa State (ollege Pres. Amer. lowa 1967).

11. Snedecor, (i. W.. and cochran. W. G.: Statistical Methods, Idd. 6. p. 135 flowa State (ollege Press. Ames, lowal. 1967).

12. Srinivatsan, S. R.. Frerichs. R. R., Webher. I. S. and Berenson. (i. S. : Serum lipoprotein profile in children from a biracial community. Circulation, 54 $3(14)(1476)$.

13. Tsing. R. ( .. Fallat. R. W.. and (ilueck. ( . J.: Cholesterel at hirth and age I (omparion of normal and hypercholesterolemic neonates. Pediatrics. 5.3 $4.58(1974)$

14. Tsang, R. ('.. and (ilueck, (', J.: Perinatal cholesterol metaholism. In: I.. A Barness, and R. M. Pitkin: (linies in Perinatolegy. Vol. 2, No, 2, pp. 275 295 (W. B. Satunders (').. Philadelphia. 1975)

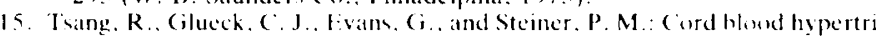
glyecridemial. Amer. J. Dis. ('hild.. 127: 78 (1974).

16. Thang, R ( Cilueck ( J Fallat, R W and Mellies M J : Neonatal familiat hypercholesterolemia. Amer. J. Dis. (hild. 129:8.3 (1975)

17. A portion of this work was supported by the (icneral ( linical Research

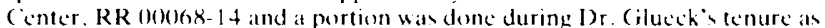
an Fstablished Investigator of the American Heart Association. 1971-1976.

18. Requeses for reprints should be addressed to: ('. J. (ilueck. M.D). (itneridl Clinical Research (enter. Cincinnati Cieneral Hospital. 234 Geodman St.. Rm. ('2-3. ('incinnati. ()hio 4.5267 (USA)

19. Received for putlication December 20.1976

20. Accopted for publication Fibruary 9. 1977

\title{
Glomerular Filtration Rate during the Period of Adaptation to Extrauterine Life
}

\author{
ROSEMARY I). I.EAKE:"W ANI) (ARI, W. TRY(SSTAD) \\ Department of Pediatrics, UCL.A School of Medicine. Harbor (ieneral Hespital, Torrance, California, USA
}

\section{Summary}

Inulin clearance $\left(C_{i 11}\right)$ was measured in 20 infants of $27-43$ weeks of gestation during the first $24 \mathrm{hr}$ of their extrauterine life. $C_{i I}$ ranged from $0.7-4.7 \mathrm{ml} / \mathrm{min}$ and correlated with gestational age $(P=0.05)$. In 18 infants of similar gestational ages studied after 2-3 days of extrauterine adaptation, the $C_{i t 1}$ ranged from
$1.1-17.9 \mathrm{ml} / \mathrm{min}$ and also correlated with gestational age $(P$. $0.01)$. By day 2-3, the infants of near term gestational age achieved a greater increase in $\mathrm{C}_{\mathrm{in}}$ than did the markedly preterm infants, as reflected by a significantly different slope of the regression line for $\mathrm{C}_{i 11}$ and gestational age for the infants studied at 1 vs. $2-3$ days of age $(P<0.001)$. 